\title{
Influence of Day and Night Temperature Differentials on Root Elongation Rate, Root Hydraulic Properties, and Shoot Water Relations in Chrysanthemum
}

\author{
Pauline Helen Kaufmann, ${ }^{1}$ Robert J. Joly, ${ }^{2}$ and P. Allen Hammer ${ }^{3}$ \\ Department of Horticulture and Landscape Architecture, Purdue University, West Lafayette, \\ IN 47907-1165
}

\begin{abstract}
AdDITIONAL INDEX wORDS. DIF, root elongation, root hydraulic conductivity, Dendranthema $\times$ grandiflora, Chrysanthemum ×morifolium

Abstract. The difference between night and day temperature (DIF = day - night temperature) has been shown to affect plant height. A positive DIF (+DIF), cooler night than day temperature, increases stem elongation while a negative DIF (DIF), warmer night than day temperature, decreases stem elongation. The physiological mechanism underlying the growth response to DIF is not understood, however, and the effects of day/night temperature differentials on root permeability to water and root elongation rate have not been studied. The objective of this study was to describe how +DIF and -DIF temperature regimes affect leaf water relations, root water flux $\left(J_{v}\right)$, root hydraulic conductivity $\left(L_{p}\right)$, and root elongation rates of 'Boaldi' chrysanthemum [Dendranthema Xgrandiflora Kitam. 'Boaldi' (syn. Chrysanthemum Xmorifolium Ramat.)] plants over time. Leaf turgor pressure $\left(\psi_{\mathrm{p}}\right)$ was 0.1 to $0.2 \mathrm{MPa}$ higher in plants grown in a $+6{ }^{\circ} \mathrm{C}$ DIF environment throughout both the light and dark periods, relative to those in a $-6^{\circ} \mathrm{C}$ DIF environment. $J_{v}$ differed markedly in roots of plants grown in +DIF vS. -DIF environments. Rhythmic diurnal patterns of $J_{v}$ were observed in all DIF treatments, but the relative timing of flux minima and maxima differed among treatments. Plants grown in positive DIF regimes exhibited maximum root flux at the beginning of the light period, while those in negative DIF environments had maximum root flux during the first few hours of the dark period. Plants grown in +DIF had significantly higher $L_{p}$ than -DIF plants. Plants grown in +DIF and -DIF environments showed differences in the diurnal rhythm of root elongation. During the dark period, +DIF plants exhibited minimal root elongation rates, while-DIF plants exhibited maximal rates. During the light period, the converse was observed. In -DIF temperature regimes, periods of rapid root elongation coincided with periods of high $J_{v}$. Results of this study suggest that negative DIF environments lead to leaf turgor reductions and markedly alter diurnal patterns of root elongation. These changes may, in turn, act to reduce stem elongation.
\end{abstract}

The floriculture market requires many crops with specific harvest date and height specifications. Until recently, chemical plant growth retardants were the major tools available for controlling stem elongation. Interest in nonchemical plant height control has increased appreciably recently because of the risk of chemical pollution of the environment and the negative public response to products treated with chemicals.

Went (1944) first described the effects of temperature differentials between light and dark periods on plant morphology and development, a phenomenon he termed thermoperiodicity. More recently, research has shown that stem elongation is highly correlated with the difference between day temperature (DT) and night temperature (NT), rather than with the actual DT and NT environments under which plants are grown (Erwin et al., 1989). Erwin et al. (1989) defined the day/night temperature differential as DIF (DIF = DT - NT), and they reported that stem elongation can be reduced by growing plants in negative DIF (-DIF) temperature regimes, where night temperatures are higher than day temperatures (Erwin and Heins, 1990; Erwin et al., 1989). The imposition of negative DIF environments subsequently has been

Received for publication 3 May 1999. Accepted for publication 2 Feb. 2000 Purdue University Office of Agricultural Research publication 15992. We thank Yoder Brothers, Inc., Barberton, Ohio, for supplying plants for this study. The cost of publishing this paper was defrayed in part by the payment of page charges. Under postal regulations, this paper therefore must be hereby marked advertisement solely to indicate this fact.

${ }^{1}$ Graduate research assistant.

${ }^{2}$ Professor

${ }^{3}$ Professor; to whom reprint requests should be addressed. adopted as a nonchemical means of plant height control in many commercial greenhouses in the northern United States; the approach has reduced substantially the number of treatments with chemical plant growth retardants (Erwin and Heins, 1995).

The physiological mechanism underlying the growth response to DIF is still not understood, although numerous hypotheses have been advanced. Some evidence suggests that DIF can bring about changes in the levels of endogenous bioactive gibberellins (Erwin et al., 1989; Moe et al., 1991; Zieslin and Tsujita, 1988). Phytochrome also has been associated with the DIF response (Erwin et al., 1989; Moe and Heins, 1990), and interactions between DIF and far red light have been suggested (Moe et al., 1991). Whether DIF acts directly to control stem elongation via specific regulatory processes or indirectly by providing a more favorable or less favorable growth environment is unknown.

Renewed interest in plant thermoperiodism and thermomorphogenic responses recently has led to numerous investigations of DIF effects on stem and leaf development. Few studies have quantified the influence of DIF on root growth, however, and there are no published reports, to our knowledge, that test the effect of DIF temperature environment on root elongation rate. Whether root growth is a continuous process or shows periodic alternation with shoot growth is not known for chrysanthemum [Dendranthema ×grandiflora 'Boaldi' (syn. Chrysanthemum $\times$ morifolium)]. If, for example, shoot and root elongation occur in alternating rhythms, this may suggest that shifting competition between these two sinks for available assimilates may be involved in the response to DIF. Furthermore, little is known about how shoot water status or root hydraulic properties are affected by 
DIF. Considering their critical roles in cell enlargement, it is of interest to quantify how these variables are affected by day and night temperature differentials. Finally, understanding how DIF temperature regimes influence root elongation and shoot water relations may suggest alternative strategies for the control of stem elongation.

The general objective of this study was to determine how day/ night temperature differentials influence root elongation and shoot water relations in chrysanthemum and to evaluate those responses in light of the known effects of DIF on stem elongation. The specific objectives were to describe how growth of plants in +DIF and-DIF temperature regimes affects leaf water potential and its osmotic and pressure components, pressure-induced root water flux, root hydraulic conductivity, and root elongation rates over time.

\section{Materials and Methods}

Plant material and initial Cultural conditions. Three separate studies were conducted from Dec. 1997 through Apr. 1998. Rooted stem cuttings of chrysanthemum were potted into 7.6- $\mathrm{cm}^{2}$ pots (T.O. Plastics Inc., Minneapolis, Minn.) using Fafard P-2 growing medium (Conrad Fafard Inc., Agawam, Maine). Plants were transferred to $0.15-\mathrm{m}^{3}$ reach-in growth chambers (model AR-75LX; Percival, Boone, Iowa) and grown for 2 to 6 weeks at the given DIF treatment. Light was supplied by cool-white fluorescent and incandescent lamps. Photosynthetic photon flux (PPF) in the region of the growing apices was maintained at $160 \pm 10 \mu \mathrm{mol} \cdot \mathrm{m}^{-2} \cdot \mathrm{s}^{-1}$ as measured with a quantum sensor (LI-COR Inc., Lincoln, Nebr.). Plants were exposed to 16$\mathrm{h}$ photoperiods, starting at 5:00 $\mathrm{AM}$ and ending at 9:00 PM. The fluorescent lamps provided $80 \%$ of the total PPF. The DIF treatments were $+8,+6,-6$, and $-8{ }^{\circ} \mathrm{C}$ with $16 \mathrm{~h}$ day $/ 8 \mathrm{~h}$ night air temperatures of $25 / 17,24 / 18,20 / 26$, and $19 / 27{ }^{\circ} \mathrm{C} \pm 1{ }^{\circ} \mathrm{C}$, respectively. The same average daily temperature of $22{ }^{\circ} \mathrm{C}$ was maintained in each DIF treatment. Vapor pressure deficits (VPD) for $+8,+6,-6$, and $-8{ }^{\circ} \mathrm{C}$ DIF were $0.2379 \pm 0.0660 / 0.1671 \pm$ $0.0569,0.2028 \pm 0.0673 / 0.2014 \pm 0.0670,0.2019 \pm 0.0670 /$ $0.1021 \pm 0.0653$, and $0.1439 \pm 0.0578 / 0.0680 \pm 0.0679 \mathrm{kPa}$ (day/ night), respectively. Vapor pressure deficit was measured with an aspirated psychrometer (Cole-Parmer Instrument Co., Vernon Hills, Ill.). Plants were placed in the chamber in a randomized block arrangement and irrigated daily at 10:00 AM to container capacity. The plants were fertilized at each watering with a $20 \mathrm{~N}-$ 4.4P-16.6K water soluble fertilizer (Scotts, Marysville, Ohio) which provided $\mathrm{N}$ at $225 \mathrm{mg} \cdot \mathrm{L}^{-1}, \mathrm{P}$ at $49 \mathrm{mg} \cdot \mathrm{L}^{-1}, \mathrm{~K}$ at $187 \mathrm{mg} \cdot \mathrm{L}^{-1}$, and micronutrients.

LEAF WATER POTENTIAL MEASUREMENTS. Rooted stem cuttings were potted 4 Dec. 1997 . The potted cuttings were placed directly into the growth chambers at a DIF temperature treatment of +6 or $-6{ }^{\circ} \mathrm{C}$. Plants were pinched $13 \mathrm{~d}$ after potting on $17 \mathrm{Dec}$. Leaf water potential $\left(\psi_{\mathrm{w}}\right)$ was measured every $3 \mathrm{~h}$ over $24 \mathrm{~h}$ starting at 12:00 PM on 24 Jan. 1998 using a pressure chamber (PMS Instruments Co., Corvallis, Ore.). Only new, fully expanded leaves from the middle of the plant were sampled. One leaf sample was taken per plant; five plants were sampled from each temperature treatment during each sampling time period. Once a leaf was severed from a plant in the growth chamber, it was immediately sealed in the pressure chamber for measurement. After leaf $\psi_{\mathrm{w}}$ of the sample was determined, the leaf was sealed immediately in a labeled zip lock polyethylene freezer bag and placed in a freezer at $-10^{\circ} \mathrm{C}$ for subsequent determination of osmotic potential $\left(\psi_{\pi}\right)$.
The $\psi_{\pi}$ of each leaf sample was determined using a Wescor 5500XR vapor pressure osmometer (Wescor Inc., Logan, Utah). The leaf samples were removed from the freezer and thawed at 21 ${ }^{\circ} \mathrm{C}$ for $10 \mathrm{~min}$. The leaf tissue was macerated quickly inside the bag using a weighted ball bearing race, and a $5-\mu \mathrm{L}$ sap sample was collected for determination of sap osmolarity. Osmotic potential was calculated as described by Saneoka et al. (1995). Leaf turgor $\left(\psi_{\mathrm{p}}\right)$ was calculated for each sample by subtracting $\psi_{\pi}$ from $\psi_{\mathrm{w}}$. Means and SE values for $\psi_{\mathrm{w}}, \psi_{\pi}$, and $\psi_{\mathrm{p}}$ were calculated for each time period sampled in each temperature treatment. The experiment was replicated three times with similar results.

ROOT WATER FLUX $\left(J_{v}\right)$ AND HYDRAULIC CONDUCTIVITY $\left(L_{p}\right)$ MEASUREMENTS. For three replications of the study, rooted cuttings were potted in July and Aug. 1997 and in Apr. 1998. Plants were transferred to the growth chambers as described above and grown for 2 weeks at the given DIF treatment. Treatments were randomized among growth chambers over time. Plants harvested were selected at random from $\approx 15$ plants in each treatment. The volume flow of water $\left(J_{v}\right)$ and root hydraulic conductivity $\left(L_{p}\right)$ of six plants within a single chamber were measured at a time; three plants each from +6 and $-6{ }^{\circ} \mathrm{C}$ DIF were measured concurrently or three plants each from +8 and $-8{ }^{\circ} \mathrm{C}$ DIF were measured concurrently.

Root systems were gently separated from the growing medium, and the stems were severed $\approx 3 \mathrm{~cm}$ above the soil level. Tissues peripheral to the vascular cambium were peeled from the upper portion of the stump of each root system to prevent axial water flow through cortical cells. Each root system was mounted singly in the lid of a stainless steel chamber filled with aerated half-strength Hoagland's solution (Hoagland and Arnon, 1950) maintained at $25^{\circ} \mathrm{C}$. Stems were first inserted through a parafilmwrapped brass tube before they were sealed into the lid of the chamber though a rubber gasket to avoid compression injury to soft tissue. The measurement system and procedures followed were as described by Joly (1989) and Maggio and Joly (1995).

After root systems were sealed in the lid, chamber pressure was increased gradually to $0.21 \mathrm{MPa}$ and held constant during measurement of flow rate, Q. Water expressed from each cut stump was delivered via tygon tubing to a system of computercontrolled valves and partitioned such that the exudate from one root system at a time was weighed by an electronic balance. Q was computed every $30 \mathrm{~min}$, and valves were automatically switched to allow sequential data collection from each of six root systems (three + DIF and three-DIF plants). Average root flux curves for each treatment were constructed by plotting mean root flux at 30min intervals over an 18 to $24 \mathrm{~h}$ time period.

Root hydraulic conductivity $\left(L_{p}\right)$ of these root systems was then measured after 18 to $24 \mathrm{~h}$, using methods described by Graves et al. (1991) and Maggio and Joly (1995). Four pressures were applied in ascending order $(0.21,0.28,0.35$, and $0.42 \mathrm{MPa})$. Flow rate was recorded for $1 \mathrm{~h}$ at each pressure, allowing a 5-min equilibration period between pressures. $L_{p}$ was estimated after making the assumption that the root can be considered, to a first approximation, a cylindrical membrane system with a radius $r$ (Fiscus and Kramer, 1975). The total length, $l$, of each root system was measured upon completion of the exudation measurements. Root diameter was obtained by sampling root cross-sections, measured to the outside of the epidermis, and an average surface area was calculated as $\pi d l . J_{v}$ was computed by transforming Q to reflect flux on the basis of the root surface area, and $L_{p}$ was estimated as the slope of the regression of $J_{v}$ on applied hydrostatic pressure (Dalton et al., 1975; Fiscus, 1977). Root hydraulic 
conductivity data were subjected to an analysis of variance.

ROOT ELONGATION RATE. Root growth of plants grown in +8 , $+6,-6$, and $-8{ }^{\circ} \mathrm{C}$ DIF regimes was measured from Nov. 1997 through Mar. 1998. Rooted cuttings having three to six roots of 1 to $3 \mathrm{~cm}$ length were used. The plants were potted into a rhizotron composed of two glass plates $(31 \times 46 \mathrm{~cm})$ set in a wooden frame. One plate was vertical while the other was angled at $15^{\circ}$ from vertical. A piece of black cotton cloth was placed on the inside of the angled glass plate. Three rooted cuttings were then attached to the angled plate, with the base of the cutting directly above the top of the black cloth, thus allowing new roots to form between the glass and cloth. Half of the roots were placed between the glass and the cotton cloth. The rhizotron contained growing medium composed of 1 medium vermiculite : 1 Fafard P-2 growing medium (v/v). The rhizotron was transferred to a $0.15-\mathrm{m}^{3}$ reachin growth chamber (Percival, Boone, Iowa) and grown for $4 \mathrm{~d}$ under a given DIF treatment before root measurements began.

A millimeter ruler was placed adjacent to an elongating root, and a VideoLabs FlexCam (VideoLabs, Inc., Minneapolis, Minn.) was positioned directly in front of the root and ruler. The camera was connected to a Power Macintosh 8500/120 PowerPC computer (Apple Computer Inc, Cupertino, Calif.), and the computer program 'Adobe Premiere' (Adobe Systems Inc., Mountain View, Calif.) was used to record root elongation over time. The rhizotron and camera were covered with a heavy black cloth to keep the root systems in darkness. A 30-W green light bulb was placed under the cloth in order to view root extension. Frames were recorded hourly throughout a 24 to 48 -h period using the stop-motion program option, and a time-lapse video was created for each root recorded. Root elongation was measured directly off the computer screen, and a root elongation rate $\left(\mathrm{mm} \cdot \mathrm{h}^{-1}\right)$ was calculated for each root. Two roots from each plant in the rhizotron were recorded in each replication, and each DIF treatment was replicated three times with runs over time and randomized among chambers. Day/night root medium temperatures measured within $1 \mathrm{~mm}$ of the glass surface were $26 / 24,26 / 24,25 / 27$, and $26 / 27^{\circ} \mathrm{C}$ in the $+8,+6,-6$, and $-8{ }^{\circ} \mathrm{C}$ DIF treatments, respectively, $\pm 1^{\circ} \mathrm{C}$.

\section{Results}

LEAF WATER POTENTIAL AND COMPONENTS. 'Boaldi' chrysanthemum plants exhibited significant treatment differences for $\psi_{\mathrm{w}}$, $\psi_{\pi}$, and $\psi_{\mathrm{p}}$ when grown in $+6{ }^{\circ} \mathrm{C}$ and $-6{ }^{\circ} \mathrm{C}$ DIF environments. Leaf $\psi_{\mathrm{w}}$ ranged between -0.35 and $-0.45 \mathrm{MPa}$ during the dark period in both DIF treatments (Fig. 1A). During the light period, $\psi_{\mathrm{w}}$ was lower in $-6{ }^{\circ} \mathrm{C}$ DIF plants than +6 DIF plants, with an average difference of $\approx 0.15 \mathrm{MPa}$ occurring between 12:00 and 4:00 PM.

The $\psi_{\pi}$ of leaf sap was higher during both the light and dark periods in plants grown in a $-6{ }^{\circ} \mathrm{C}$ DIF environment, relative to those grown at $+6^{\circ} \mathrm{C} \mathrm{DIF} \mathrm{(Fig.} \mathrm{1B).} \mathrm{In} \mathrm{both} \mathrm{positive} \mathrm{and} \mathrm{negative}$ DIF treatments, $\psi_{\pi}$ was lowest at the end of the light period, reaching a value of $-1.09 \mathrm{MPa}$ for $+6{ }^{\circ} \mathrm{C}$ DIF and $-1.33 \mathrm{MPa}$ for $-6{ }^{\circ} \mathrm{C}$ DIF. $\psi_{\pi}$ increased during the dark period in +6 and $-6{ }^{\circ} \mathrm{C}$ DIF treatments, reaching its highest values near the end of the dark period or the beginning of the subsequent light period.

$\psi_{\mathrm{p}}$ was generally higher in plants grown in the $+6{ }^{\circ} \mathrm{C}$ DIF environment throughout both the light and dark periods (Fig. 1C). Further, for both DIF treatments, $\psi_{\mathrm{p}}$ was higher during the dark than during the light period. During the first $3 \mathrm{~h}$ of the dark period, $\psi_{\mathrm{p}}$ in leaves of +6 DIF plants was $\approx 0.2 \mathrm{MPa}$ higher than that measured in -6 DIF plants.
ROOT WATER FLUX $\left(J_{v}\right)$ AND HYDRAULIC CONDUCTIVITY $\left(L_{p}\right)$ MEASUREMENTS. Pressure-induced root water flux differed markedly in roots of chrysanthemum plants grown in +DIF vs. -DIF environments. Rhythmic diurnal patterns of root water flux were observed in all four DIF treatments, but the relative timing of flux minima and maxima differed among those treatments. Plants grown at +6 or $+8^{\circ} \mathrm{C}$ DIF regimes exhibited minimum or near minimum root flux at the beginning of the dark period and near maximum root flux in the light period (Figs. 2A and 3A). In contrast, plants grown at -6 or $-8^{\circ} \mathrm{C}$ DIF regimes exhibited near minimum root flux near the midpoint of the light period and near maximum root flux during the first few hours of the dark period (Figs. 2B and 3B). The diurnal patterns of root water flux observed for plants grown in +DIF and -DIF environments appear to be shifted from each other by $\approx 8 \mathrm{~h}$.

The mean root $L_{p}$ values of plants grown at +6 and $-6^{\circ} \mathrm{C}$ DIF regimes were greater than those of plants grown at +8 and $-8^{\circ} \mathrm{C}$ DIF regimes (Table 1). Furthermore, +DIF plants had roots with significantly higher $L_{p}$ than roots of -DIF plants (Table 2).

RoOT ELONGation Rate. The timing of root elongation differed markedly for chrysanthemum plants grown in +DIF vs. DIF environments. A diurnal pattern of root elongation rate was
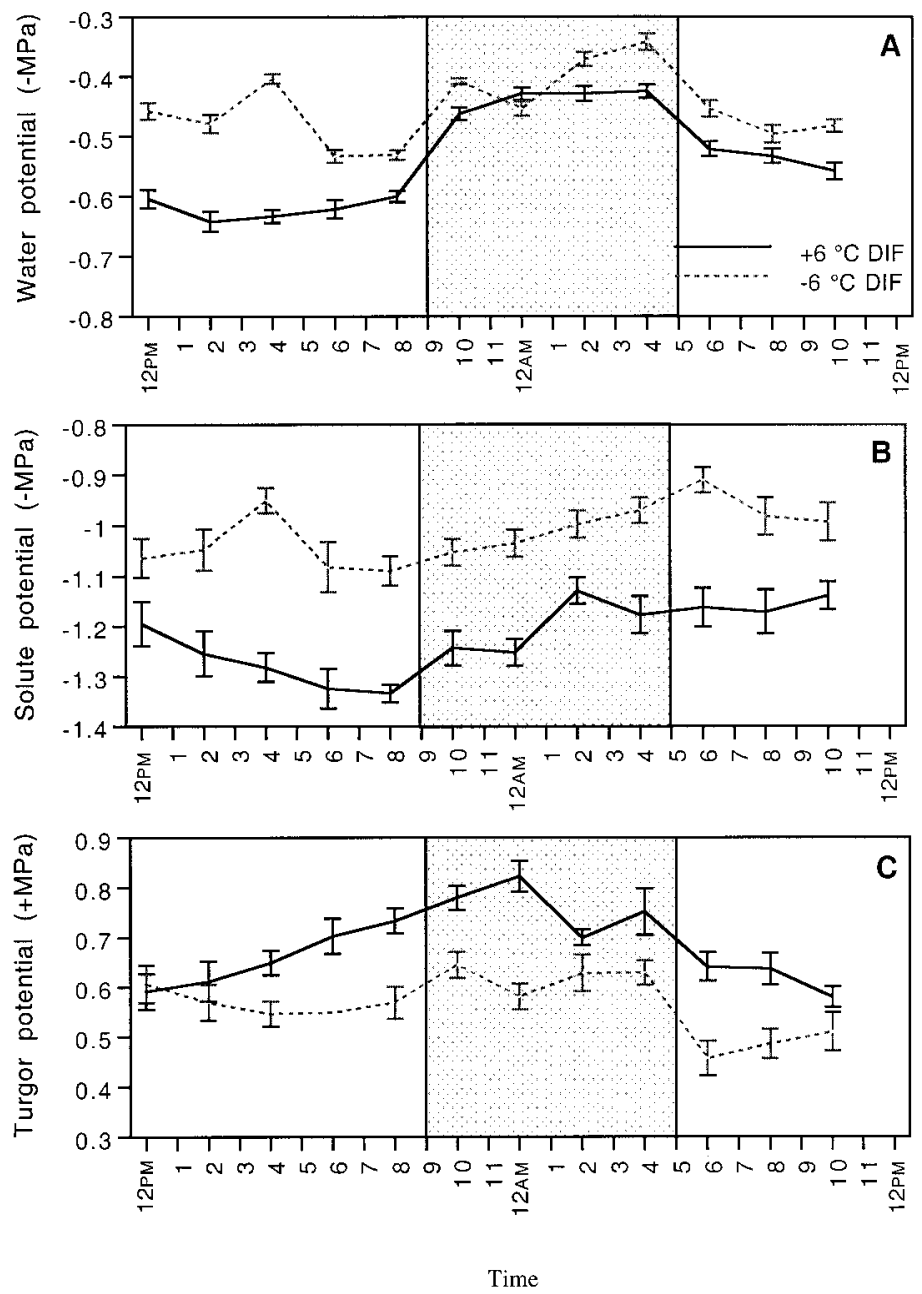

Fig. 1. (A) Leaf water potential, (B) solute potential, and (C) leaf turgor potential of 'Boaldi' chrysanthemum grown at +6 and $-6{ }^{\circ} \mathrm{C}$ DIF temperature regimes. Five plants were sampled once every $2 \mathrm{~h}$ over $24 \mathrm{~h}$. Means and SE values (vertical bars) were calculated at each sampling period. Shaded area represents the 8-h night period; DT/NT $=24 / 18^{\circ} \mathrm{C}$ at $+6{ }^{\circ} \mathrm{C}$ DIF and $20 / 26{ }^{\circ} \mathrm{C}$ at $-6{ }^{\circ} \mathrm{C}$ DIF. 

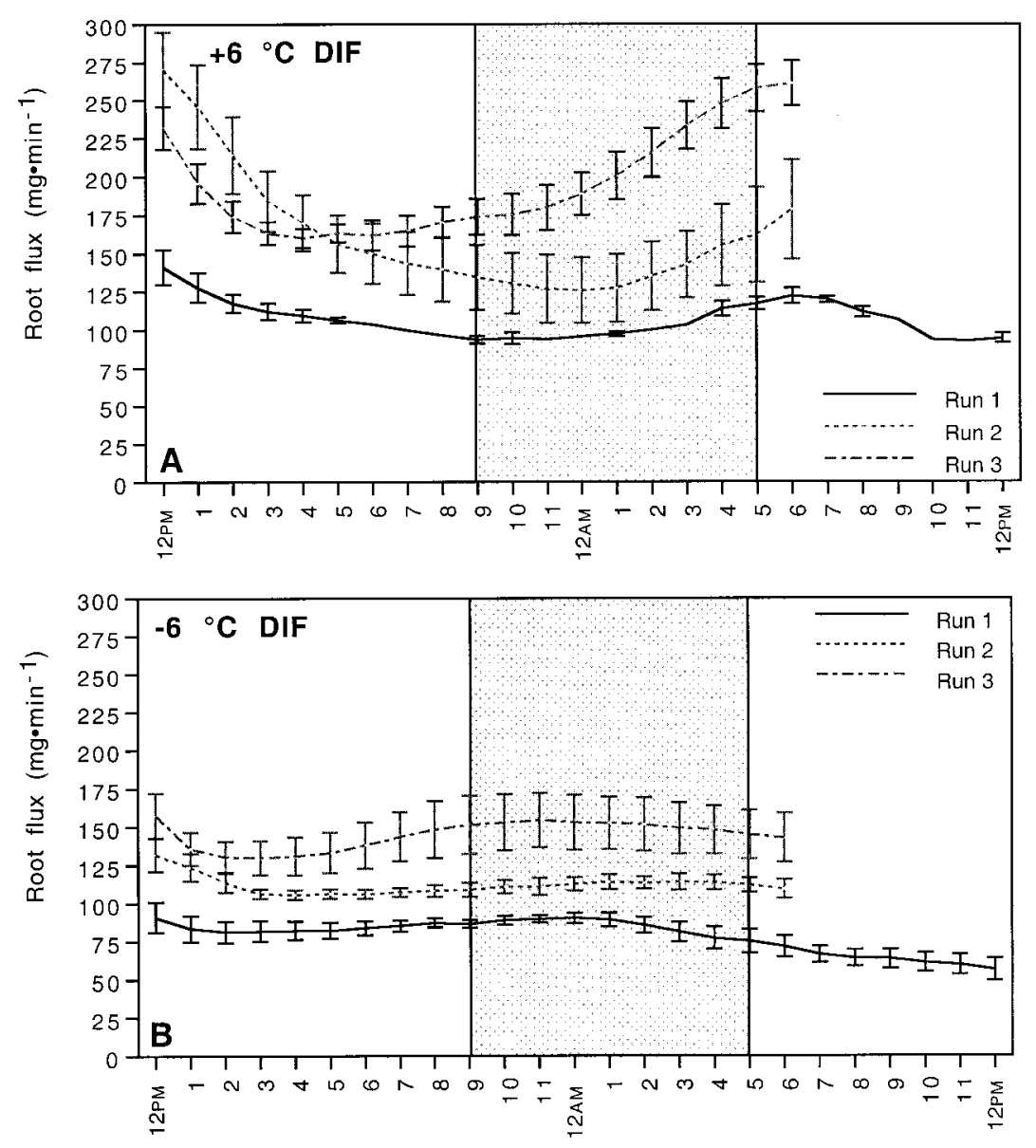

Time
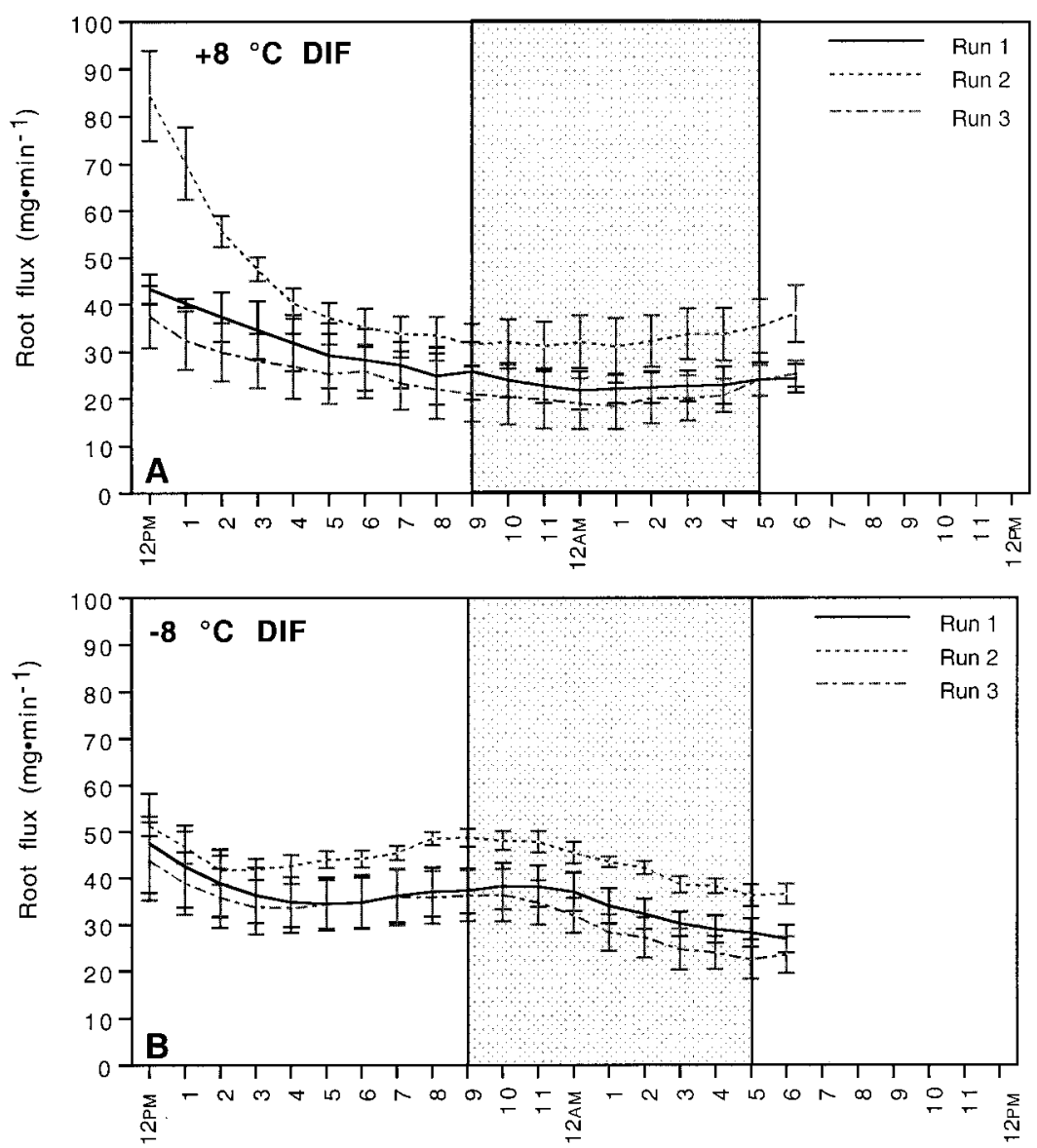

Time
Fig. 2. Effect of (A) +6 and $(\mathbf{B})-6{ }^{\circ} \mathrm{C}$ DIF temperature treatment on pressure-induced root water flux in 'Boaldi' chrysanthemum. Root water flux of three root systems per run were measured hourly over 18 to $24 \mathrm{~h}$. Shaded area represents the 8 -h night period; DT/NT $=24 / 18{ }^{\circ} \mathrm{C}$ at $+6{ }^{\circ} \mathrm{C}$ DIF and $20 / 26^{\circ} \mathrm{C}$ at $-6^{\circ} \mathrm{C}$ DIF. Run represents the replication of the treatment. Vertical bars are SE values.

observed in all four DIF treatments. The minimum and maximum root elongation rates were $\approx 0.25$ and $0.6 \mathrm{~mm} \cdot \mathrm{h}^{-1}$, respectively, regardless of the DIF environment. However, the timing of minimum and maximum root elongation differed greatly between + DIF and -DIF treatments. Plants grown in a +6 or $+8{ }^{\circ} \mathrm{C}$ DIF environment exhibited minimum root elongation rates near the end of the dark period and maximum elongation rates near the end of the light period (Figs. 4A and 5A). In contrast, plants grown in a -6 or $-8{ }^{\circ} \mathrm{C}$ DIF environment exhibited minimum root elongation rates during the middle of the light period and maximum elongation rates during the dark period.

The relative timing of maximum root elongation rate varied between the two -DIF treatments (Figs. $4 \mathrm{~B}$ and $5 \mathrm{~B}$ ). Plants grown in the $-6{ }^{\circ} \mathrm{C}$ DIF environment had maximum elongation rates during the final half of the dark period, while those in the $-8^{\circ} \mathrm{C}$ DIF environment had maximum rates during the first half of the dark period.

\section{Discussion}

'Boaldi' chrysanthemum plants grown in +DIF vs. -DIF environments differed from each other for leaf turgor pressure (Fig. 1), diurnal patterns of root water flux (Figs. 2 and 3), root hydraulic conductivity (Table 2), and the relative timing of maximal and minimal root elongation rates (Figs. 4 and 5). A novel and remarkable outcome of these experiments is the effect of DIF temperature regime on root elongation rates throughout the light/dark cycle (Figs. 4 and 5). Plants grown in +DIF and -DIF environments show a reversal in the diurnal rhythm of root elongation. During the dark period, +DIF plants exhibited minimal root elongation rates, while -DIF plants exhibited maximal rates. During the light period, the converse was observed.

The underlying reason for the altered diurnal pattern of root elongation is unknown. No consistent relationship between pressure-induced root water flux and root elongation rate was evident across both positive and negative DIF treatments. However, two associations were apparent among plants grown in-DIF regimes. First, root water flux and root elongation rates both increased at the beginning of the dark period in plants grown in DIFenvironments (Figs. 2-5). Second, plants grown

Fig. 3. Effect of $(\mathbf{A})+8$ and $(\mathbf{B})-8{ }^{\circ} \mathrm{C}$ DIF temperature treatment on root water flux in 'Boaldi' chrysanthemum. Root water flux of three root systems per run were measured hourly over 18 to 24 h. Shaded area represents 8 -h night period; DT/NT $=25 / 17^{\circ} \mathrm{C}$ at $+8{ }^{\circ} \mathrm{C}$ DIF and $19 / 27{ }^{\circ} \mathrm{C}$ at $-8{ }^{\circ} \mathrm{C}$ DIF. Run represents the replication of the treatment. Vertical bars are SE values. 
Table 1. Root hydraulic conductivity $\left(L_{p}\right)$ of 'Boaldi' chrysanthemum grown at $+6,-6,+8$, and $-8{ }^{\circ} \mathrm{C}$ DIF temperature regimes. Hydraulic conductivity of three root systems for each run was determined. Means and SEs were calculated for each run.

\begin{tabular}{lccc}
\hline \hline & & \multicolumn{2}{c}{ Mean $L_{p}$} \\
\cline { 2 - 4 } Treatment $^{\mathrm{z}}$ & $\mathrm{Run}^{\mathrm{y}}$ & $\left(\mathrm{m} \cdot \mathrm{s}^{-1} \cdot \mathrm{MPa}^{-1}\right) \times 10^{-7}$ & $\mathrm{SE}$ \\
\hline$+8{ }^{\circ} \mathrm{C} \mathrm{DIF}$ & 1 & 1.75 & $3.35 \times 10^{-8}$ \\
& 2 & 1.46 & $4.20 \times 10^{-8}$ \\
& 3 & & $6.97 \times 10^{-8}$ \\
$+6{ }^{\circ} \mathrm{C}$ DIF & 1 & 2.72 & $8.57 \times 10^{-9}$ \\
& 2 & 2.52 & $1.48 \times 10^{-8}$ \\
& 3 & 1.90 & $3.10 \times 10^{-8}$ \\
$-6{ }^{\circ} \mathrm{C}$ DIF & 1 & & \\
& 2 & 2.31 & $3.68 \times 10^{-8}$ \\
& 3 & 2.16 & $2.29 \times 10^{-8}$ \\
$-8{ }^{\circ} \mathrm{C}$ DIF & 1 & 2.28 & $5.37 \times 10^{-9}$ \\
& 2 & & \\
& 3 & 1.58 & $2.10 \times 10^{-8}$ \\
& & 1.97 & $1.35 \times 10^{-8}$ \\
\hline
\end{tabular}

${ }^{\mathrm{Z}}$ Difference between day temperature and night temperature; $+8,+6,-6$, and $-8{ }^{\circ} \mathrm{C}$ DIF $=25 / 17,24 / 18,20 / 26$, and $19 / 27^{\circ} \mathrm{C}(16 \mathrm{~h}$ day $/ 8 \mathrm{~h}$ night temperature), respectively. Average daily temperature, $22^{\circ} \mathrm{C}$.

${ }^{\mathrm{y}}$ Replication of the treatment.

Table 2. Analysis of variance for root hydraulic conductivity $\left(L_{p}\right)$ of 'Boaldi' chrysanthemum plants grown in +DIF and -DIF temperature regimes.

\begin{tabular}{|c|c|c|c|c|}
\hline Parameter & df & $\mathrm{ms}$ & $F$ & $P$ \\
\hline \multicolumn{5}{|l|}{ Treatments } \\
\hline+ DIF $^{z}$ vs. - DIF & 1 & 3.458 & 17.13 & 0.01 \\
\hline$+6^{\circ} \mathrm{C}$ DIF vs. $-6^{\circ} \mathrm{C}$ DIF & 1 & 0.082 & 0.47 & NS \\
\hline$+8^{\circ} \mathrm{C}$ DIF vs. $-8^{\circ} \mathrm{C}$ DIF & 1 & 0.002 & 0.01 & NS \\
\hline $\operatorname{Run}^{\mathrm{y}}$ & 2 & 0.537 & 2.66 & NS \\
\hline Run vs. treatment & 6 & 0.174 & 0.86 & NS \\
\hline Error & 24 & 0.202 & & \\
\hline
\end{tabular}

${ }^{\mathrm{z}}$ Difference between day temperature and night temperature; $+8,+6,-6$, and $-8{ }^{\circ} \mathrm{C}$ DIF $=25 / 17,24 / 18,20 / 26$, and $19 / 27^{\circ} \mathrm{C}(16 \mathrm{~h}$ day $/ 8 \mathrm{~h}$ night temperature), respectively. Average daily temperature, $22^{\circ} \mathrm{C}$.

y'Replication of the treatment.

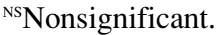

in -DIF environments showed minimal root water flux and minimal root elongation during the light period. No consistent relationship between root water flux and root elongation rate was detected in plants grown in +DIF environments.

As noted above, the root elongation rate of plants grown in DIF temperature regimes was associated with root water flux. Periods of rapid elongation coincided with periods of high root water flux, suggesting that elongation may have been facilitated by higher root permeability to water. However, our experiments cannot resolve cause and effect, and an alternative explanation that root water flux was itself affected by root growth cannot be excluded. Ivanov (1980), citing earlier work by Russian investigators, suggested that daily periodicity in root pressure exudation was related to daily cycles of cell division and root growth. This hypothesis appears to be supported by Bunce (1978) who reported that increased root hydraulic resistance was correlated with decreased root elongation.
Root temperature was not controlled in these studies. Although we did not observe large root medium temperature differences, these studies can not assess the effect of root temperature differences. Certainly the commercial application of DIF would be similar to our results as root temperature is generally not controlled.

Root hydraulic conductivity $\left(L_{p}\right)$ was significantly lower in plants grown in -DIF environments than in +DIF environments (Tables 1 and 2). Because $L_{p}$ defines the ability of the root system to supply water to growing cells, it could, in theory, affect stem elongation. Any reduction in $L_{p}$ brought about by a-DIF environment would act to steepen the water potential gradient between growing and absorbing regions. The net effect would be a lower rate of water delivery to the shoot and a concomitant reduction in stem elongation. However, although analysis of variance showed that $L_{p}$ values differed at $P<0.01$ in + DIF and -DIF plants, it should be noted that $L_{p}$ measured in root systems of -DIF plants was only $\approx 4 \%$ lower than that in +DIF plants. It is unlikely that such a small difference in root permeability to water could result in appreciable differences in stem elongation.

Leaf turgor pressure of new fully expanded leaves differed in relative magnitude but not in periodicity for + DIF and -DIF plants (Fig. 1C). Leaf $\psi_{\mathrm{p}}$ was higher in +DIF plants at most times during the 24-h light/dark cycle, with the exception of the middle $6 \mathrm{~h}$ of the light period. During the dark period, $\psi_{\mathrm{p}}$ was $\approx 0.15 \mathrm{MPa}$ higher, on average, in +DIF plants than in-DIF plants. The steady increase in leaf $\psi_{\mathrm{p}}$ observed in +DIF plants during the final $8 \mathrm{~h}$ of the light period was likely the result of the concomitant decline in $\psi_{\pi}$ during this period (Fig. 1B). It is notable that although leaf $\psi_{\mathrm{p}}$ increased in +DIF plants to its highest level during the first $3 \mathrm{~h}$ of the dark period, root elongation rate actually decreased during this period. This suggests that high turgor pressure in the shoot is not associated with root elongation processes. We did not measure leaf turgor pressure of expanding leaves in this study. It would be interesting to study that tissue during the expansion phase in relation to DIF treatments.

Shoot elongation rates were not measured in this study, so the relative kinetics of root and shoot growth cannot be quantified. Nevertheless, numerous studies have shown maximum stem elongation occurs at sunrise in chrysanthemum plants grown in +DIF environments and at the beginning of the dark period in DIF environments (Bertram and Karlsen, 1994; Erwin and Heins, 1990; Erwin et al., 1992; Tutty et al., 1994). The observation that maximum leaf $\psi_{\mathrm{p}}$ was reached during the first $3 \mathrm{~h}$ of the dark period in both +DIF and -DIF plants (Fig. 1C) suggests that a simple hypothesis invoking turgor-driven stem elongation cannot fully explain the reports of shoot growth differences in the +DIF and -DIF environments. Nevertheless, several observations point to at least a partial role for turgor in stem elongation. First, leaf $\psi_{\mathrm{p}}$ was nearly always higher in +DIF plants than in DIF plants throughout the 24-h measurement period. Further, although $\psi_{\mathrm{p}}$ increased during the early hours of the dark period in both +DIF and -DIF plants, its rate of increase was greater in + DIF plants. Thus, although periods of maximal $\psi_{p}$ do not coincide with periods of maximal stem elongation, greater stem elongation was, in general, associated with higher $\psi_{\mathrm{p}}$.

Growth is controlled in a complex fashion by turgor, cell-wall extensibility, and membrane permeability to water. Pritchard (1994) and Wu et al. (1996) reported that cell expansion was controlled principally by cell-wall extensibility rather than by the prevailing turgor pressure in the elongating region, for example. Future studies where growth, wall extensibility, and turgor are 

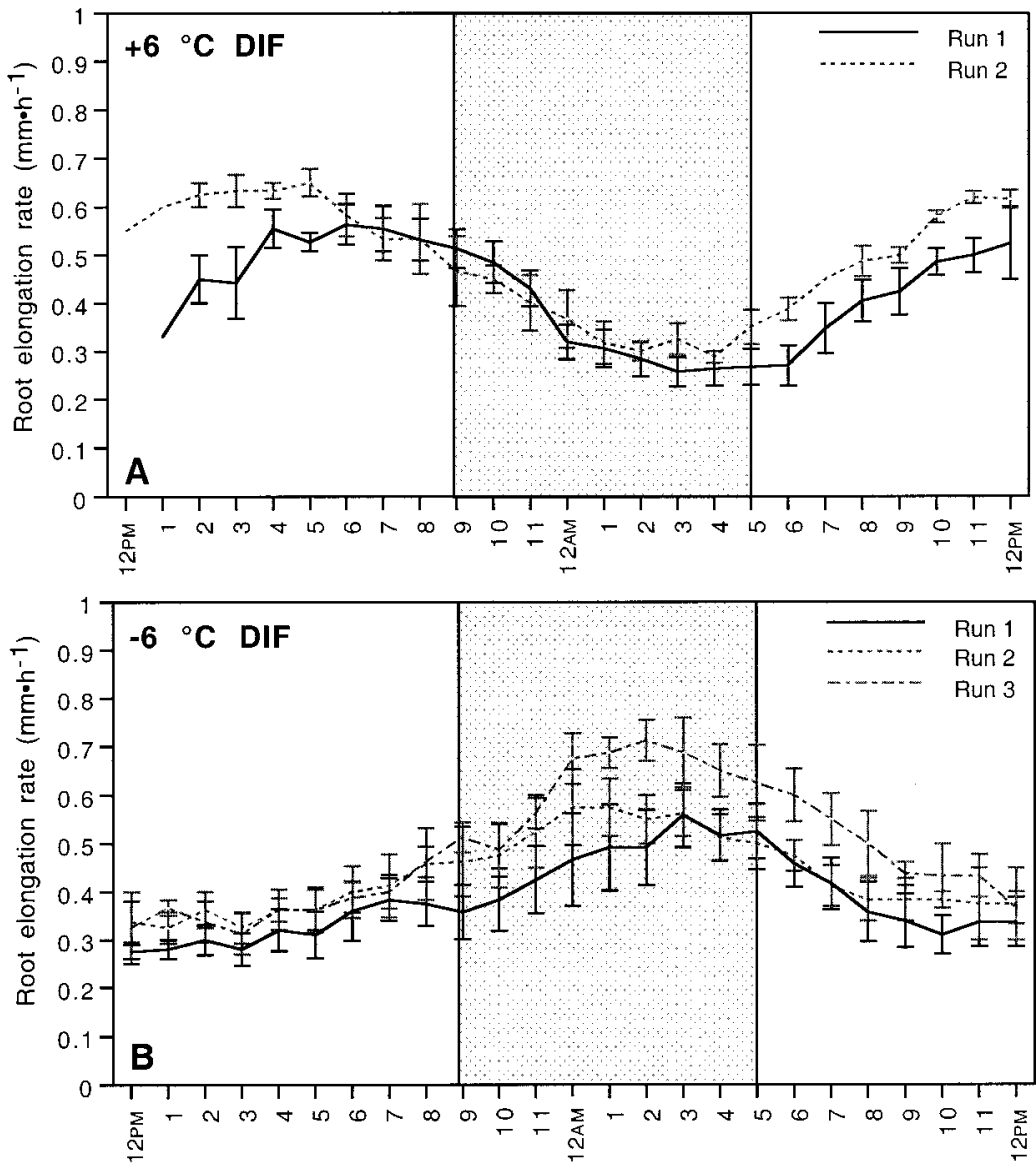

Time
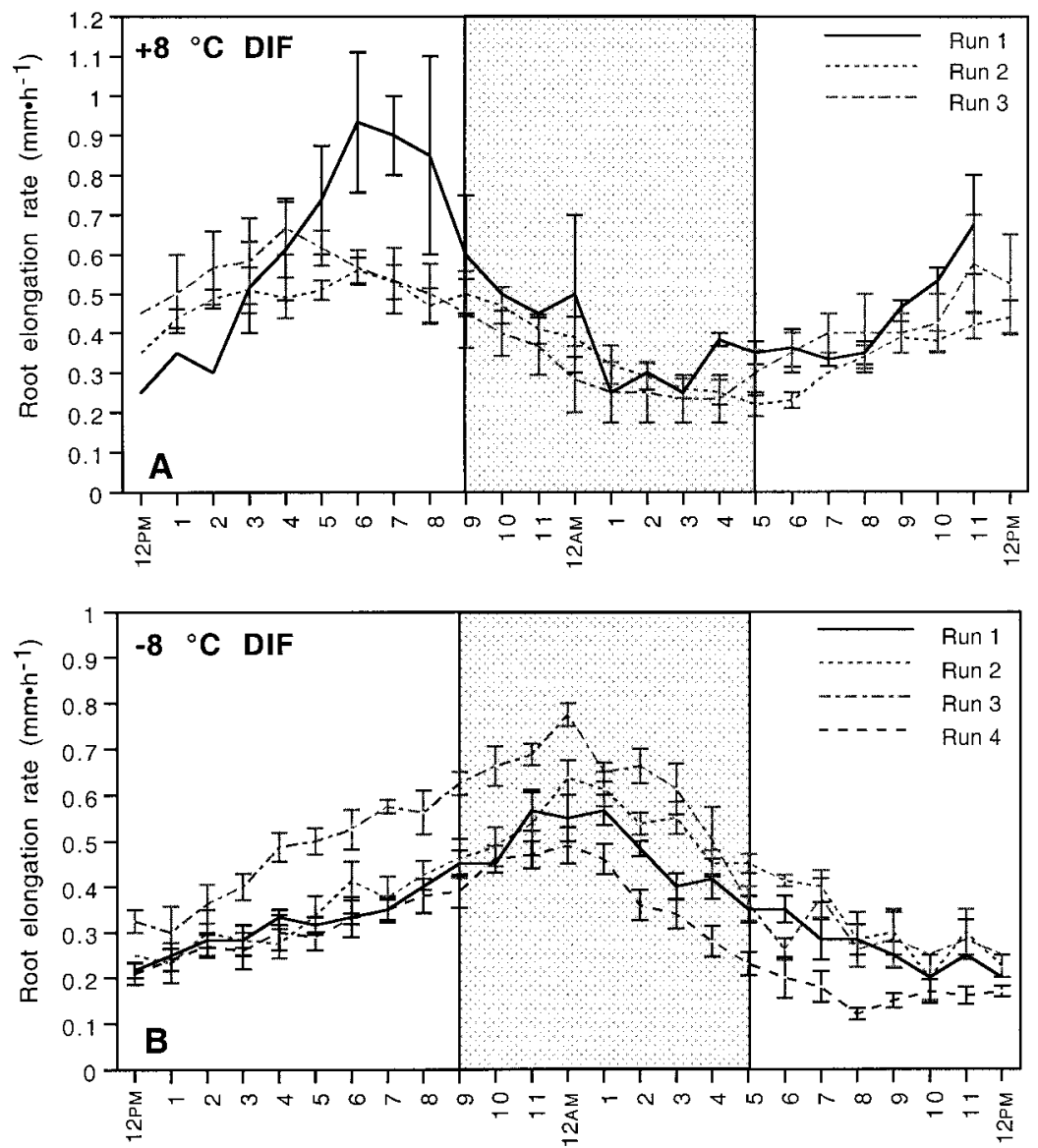

Fig. 4. Effect of (A) +6 and $(\mathbf{B})-6^{\circ} \mathrm{C}$ DIF temperature treatment on root elongation in 'Boaldi' chrysanthemum. Root elongation rates of six roots (two roots/plant) in each experiment were determined each hour over $24 \mathrm{~h}$. Hourly means and SE values (vertical bars) were calculated for each run. Shaded area represents the 8-h night period; $\mathrm{DT} / \mathrm{NT}=24 / 18{ }^{\circ} \mathrm{C}$ at $+6{ }^{\circ} \mathrm{C}$ DIF and $20 / 26^{\circ} \mathrm{C}$ at $+6{ }^{\circ} \mathrm{C}$ DIF. Run represents the replication of the treatment.

evaluated concurrently will be helpful in identifying those biophysical properties that change most rapidly in response to temperature reversals.

The physiological mechanism(s) underlying the effect of DIF environment on the diurnal pattern of root elongation remain to be elucidated. Neither leaf $\psi_{\mathrm{p}}$ nor root hydraulic properties appear to be directly related to the well-defined diurnal patterns of root elongation. It is interesting to note that the root elongation rate minima shown in Figs. 4 and 5 occur $\approx 4$ to $6 \mathrm{~h}$ in advance of the widely reported stem elongation rate maxima, regardless of whether the DIF treatment is positive or negative. This suggests that root and shoot growth in chrysanthemum may occur in alternating pulses and that the DIF environment may influence metabolic processes governing carbon allocation and/ or partitioning. The rate of root elongation in many species has been shown to vary in relation to shoot development (Reich et al., 1980; Thaler and Pages, 1996). Reich et al. (1980) reported that in a constant environment, seedlings of several oak (Quercus L.) species underwent a series of synchronous flushes of shoot growth alternating with periods of root growth. Appreciable root growth occurred only while leaves and shoots were not growing.

The well-described reduction in stem elongation induced by growing plants in a -DIF temperature regime (Erwin and Heins, 1990; Erwin et al., 1989) may be related to the apparent shift in the timing of root elongation reported herein. Mobilization of available photosynthate towards rapidly elongating roots during the midportion of the dark period in DIF plants may decrease the supply of carbon available to support rapid stem elongation, which normally would occur at sunrise in +DIF environments. This hypothesis could be tested by measuring the effects of day and night temperature differentials on the kinetics of root and shoot growth and on the synchrony of movement of labeled carbon to these organs.

\section{Literature Cited}

Bertram, L. and P. Karlsen. 1994. Patterns in stem elongation rate in chrysanthemum and tomato plants in relation to irradiance and day/night temperature. Scientia Hort. 58:139-150.

Bunce, J.A. 1978. Effects of shoot environment on apparent root resistance to water flow in whole soybean and

Fig. 5. Effect of (A) +8 and $(\mathbf{B})-8{ }^{\circ} \mathrm{C}$ DIF temperature treatment on root elongation in 'Boaldi' chrysanthemum. Root elongation rates of six roots (two roots per plant) in each experiment were determined each hour over $24 \mathrm{~h}$. Hourly means and SE values (vertical bars) were calculated for each run. Shaded area represents the night period; DT/NT $=25 / 17^{\circ} \mathrm{C}$ at $+8^{\circ} \mathrm{C}$ DIF and $19 / 27^{\circ} \mathrm{C}$ at $-8{ }^{\circ} \mathrm{C}$ DIF. Run represents the replication of the treatment. 
cotton plants. J. Expt. Bot. 29:595-601.

Dalton, F.N., P.A.C. Raats, and W.R. Gardner. 1975. Simultaneous uptake of water and solutes by plant roots. Agron. J. 67:334-339.

Erwin, J.E. and R.D. Heins. 1990. Temperature effects on lily development rate and morphology from the visible bud stage until anthesis. J. Amer. Soc. Hort. Sci. 115:644-646.

Erwin, J.E. and R.D. Heins. 1995. Thermomorphogenic responses in stem and leaf development. HortScience 30:940-949.

Erwin, J.E., R.D. Heins, W.H. Carlson, and S. Newport. 1992. Environmental and mechanical manipulation of stem elongation. Plant Growth Regulator Soc. Amer. Quarterly 20:1-17.

Erwin, J.E., R.D. Heins, and M.G. Karlsson. 1989. Thermomorphogenesis in Lilium longiflorum. Amer. J. Bot. 76:47-52.

Fiscus, E.L. 1977. Determination of hydraulic and osmotic properties of soybean root systems. Plant Physiol. 59:1013-1020.

Fiscus, E.L. and P.J. Kramer. 1975. General model for osmotic and pressure induced flow in plant roots. Proc. Natl. Acad. Sci. USA 72:3114-3118.

Graves, W.R., R.J. Joly, and M.N. Dana. 1991. Water use and growth of honey locust and tree-of-heaven at high root-zone temperature. HortScience 26:1309-1312.

Hoagland, D.R. and D.I. Arnon. 1950. The water-culture method for growing plants without soil. Univ. Calif. Agr. Expt. Sta. Circ. 347.

Ivanov, V.B. 1980. Specificity of spatial and time organization of root cell growth in connection with functions of the root. Soviet Plant Physiol. 26:720-728.

Joly, R.J. 1989. Effects of sodium chloride on the hydraulic conductivity of soybean root systems. Plant Physiol. 91:1262-1265.

Maggio, A. and R.J. Joly. 1995. Effects of mercuric chloride on the hydraulic conductivity of tomato root systems. Evidence for a channel- mediated water pathway. Plant Physiol. 109:331-335.

Moe, R. and R. Heins. 1990. Control of plant morphogenesis and flowering by light quality and temperature. Acta Hort. 272:81-89.

Moe, R., R.D. Heins, and J. Erwin. 1991. Stem elongation and flowering of the long-day plant Campanula isophylla 'Moretti' in response to day and night temperature alterations and light quality. Scientia Hort. 48:141-151.

Pritchard, J. 1994. The control of cell expansion in roots. New Phytol. 127:3-26.

Reich, P.B., R.O. Tesky, P.S. Johnson, and T.M. Hinckley. 1980. Periodic root and shoot growth in oak. For. Sci. 26:590-598.

Saneoka, H., C. Nagasaka, D.T. Hahn, W.-J. Yang, G.S. Premachandra, R.J. Joly, and D. Rhodes. 1995. Salt tolerance of glycinebetainedeficient and -containing maize lines. Plant Physiol. 107:631-638.

Thaler, P. and L. Pages. 1996. Root apical diameter and root elongation rate of rubber seedlings (Hevea brasiliensis) show parallel responses to photoassimilate availability. Physiol. Plant. 97:365-371.

Tutty, J.R., P.R. Hickleton, D.N. Kristie, and K.B. McRae. 1994. The influence of photoperiod and temperature on the kinetics of stem elongation in Dendranthema grandiflorum. J. Amer. Soc. Hort. Sci. 119:138-143.

Went, F.W. 1944. Plant growth under controlled conditions. II. Thermoperiodicity in growth and fruiting of the tomato. Amer. J. Bot. 31:135150.

Wu, Y., R.E. Sharp, D.M. Durachko, and D.J. Cosgrove. 1996. Growth maintenance of the maize primary root at low water potentials involves increases in cell-wall extension properties, expansin activity, and wall susceptibility to expansins. Plant Physiol. 111:765-772.

Zieslin, N. and M.J. Tsujita. 1988. Regulation of stem elongation of lilies by temperature and the effect of gibberellin. Scientia Hort. 37:165-169. 